\title{
Resenha: Perspectives on cognitive task analysis: historical origins and modern communities of practice
}

Review: Perspectives on cognitive task analysis: historical origins and modern communities of practice

Reseña: Perspectives on cognitive task analysis: historical origins and modern communities of practice

Hoffman, R. R. \& Militello, L. G. (2009). Perspectives on cognitive task analysis: historical origins and modern communities of practice. New York, NY: Taylor \& Francis.

Idonézia Collodel Benetti*

análise cognitiva da tarefa (ACT) (“cognitive task analysis" - CTA) é
empregada para determinar os processos mentais que os indivíduos
realizam ao desempenhar suas atividades, focando as demandas cognitivas individuais, incluindo a memória, a atenção e a capacidade de tomar decisôes. Assim, essa é uma abordagem que tem demonstrado eficácia pelo fato de capturar descriçôes, precisas e completas, de decisões e processos cognitivos, oferecendo ao profissional investigador condiçôes de extrair informaçôes sobre as demandas e as habilidades cognitivas exigidas na execução de tarefas.

Nesse sentido, a ACT pode ser indicada quando uma tarefa é considerada complexa, incerta, difícil de ser executada, e quando envolve tomada de decisão ou trabalho em equipe. É oportuno salientar que suas raízes estão em estudos clássicos oriundos da teoria da aprendizagem, aplicados à Administração Científica, combinando tempos e movimentos; outras áreas do conhecimento, tais como a Psicologia Educacional e a Engenharia de Softwares (e também fatores humanos) ${ }^{1}$ contribuíram para o fortalecimento e emergência dessa abordagem.

No que diz respeito ao termo "comunidades de prática” (“communities of practice" - CoP), pode-se afirmar que sua cunhagem é relativamente

\footnotetext{
Mestranda em Psicologia na Universidade Federal de Santa Catarina (UFSC), professora do Centro Universitário BarrigaVerde e psicóloga. Rua Pe. João Leonir Dall'Alba, s/nº - Bairro Murialdo, Orleans-SC. CEP 88870-000. E-mail: idonezia@ hotmail.com.

Fatores humanos, nessa obra, referem-se à análise da interação humana relacionada ao desenvolvimento de mecanismos, ferramentas e máquinas, aplicadas a equipes de trabalho e vários outros aspectos atrelados à configuração do trabalho e das organizaçōes.
} 
recente, apesar de que o fenômeno a que ele se refere é bastante antigo. Essas comunidades são formadas por pessoas preocupadas e engajadas em processos de aprendizagem coletiva em uma determinada área de conhecimento, na tentativa de compartilhar e explorar novas formas de "fazer melhor" e aprender sobre algo que é comum a todos os participantes da mesma comunidade.

É prudente apontar que é importante entender a natureza das tarefas, na intenção de tornar o trabalho mais interessante, sendo um desafio procurar estratégias para aumentar a produtividade. Nesse sentido, profissionais de diferentes contextos de trabalho consideram essa abordagem útil e procuram utilizá-la como ferramenta vital para aumentar a performance de suas equipes de trabalho.

Albergando temas relacionados à análise cognitiva de tarefas e às comunidades de prática/trabalho está a obra "Perspectives on cognitive task analysis historical: origins and modern communities of practice", de autoria de Laura Militello (psicóloga pesquisadora do Instituto de Pesquisa da Universidade de Dayton, Ohio, EUA) e Robert Hoffman (membro da Sociedade Americana de Psicologia, da Sociedade de Ergonomia e Fatores Humanos, da Associação Americana para a Inteligência Artificial, e da Sociedade Internacional de Psicologia do Meio Ambiente).

Publicada pela Psychology Press (EUA) em 2009, essa obra faz parte da série "Expertise: research and applications series", ${ }^{1}$ e tem como principal atributo sublinhar a importância dos métodos de análise cognitiva da tarefa na compreensão das demandas cognitivas de determinadas atividades, bem como o conhecimento e a extensão que estão encapsulados no desempenho destas, tendo como contexto algumas comunidades de trabalho. Contendo 516 páginas, esse volume está dividido em três partes:

1) Parte 1: História - Composta por cinco artigos que apresentam a descrição de uma variedade de técnicas relacionadas à $\mathrm{ACT}$, suas características comuns e as estratégias típicas usadas para evocar conhecimentos provenientes de recursos e de experts da área: 1) Introdução à primeira parte; 2) A história da análise da tarefa; 3) Evolução da análise da tarefa até a análise cognitiva da tarefa; 4) Definindo e estabelecendo as fronteiras da análise cognitiva da tarefa; e 5) Emergência das comunidades de prática/trabalho.

2) Parte 2: "Perspectivas" - Apresenta sete trabalhos que discutem a integração da ACT e do treinamento em tarefas para áreas específicas: 1) Introdução à segunda parte; 2) As "perspectivas"; 3) Engenharia de sistemas

\footnotetext{
“Conhecimento especializado: série pesquisa e aplicações” (tradução da autora).
} 
cognitivos; 4) Estudos especializados; 5) Tomada de decisão; 6) Análise do trabalho; 7) Perspectivas sociológicas e etnográficas; e 7) Computação centrada na pessoa.

3) Parte 3: Sintese - Tem cinco capítulos que descrevem o impacto das pesquisas em ACT, sintetizando um número de estudos e revisões pertinentes a assuntos que envolvem a ACT e as comunidades de trabalho: 1) Introdução à terceira parte; 2) Divergência das perspectivas; 3) Convergências das perspectivas; 4) Convergência sobre o tópico relacionado a grupo de trabalho e grupo de cognição; e 5) Desafios metodológicos para a análise cognitiva da tarefa.

Como apontado pela obra, novas tecnologias introduzidas no espaço laboral têm permitido o crescimento da automação, transferindo o foco central de muitos trabalhos para atividades mais estratégicas e de solução de problemas. Então os métodos de análise cognitiva da tarefa podem ser usados efetivamente para antecipar a performance frente aos problemas e especificar maneiras para aumentar o desempenho individual e da equipe de trabalho.

Entre os benefícios trazidos pela ACT está a identificação de mudanças nas estruturas de conhecimento e nos processos mentais, quando comparado o progresso, de um estágio de conhecimento para outro, entre estreantes e experts, já que essa metodologia visa a oferecer ganhos essenciais por apresentar os seguintes componentes: acesso às habilidades individuais e às mudanças no conhecimento de base, identificação dos componentes de uma tarefa e das diferenças entre iniciantes e veteranos, identificação de conhecimentos conceituais e de procedimentos sequenciais de componentes similares, e especificação de condiçôes que facilitam e esclarecem a progressão de um patamar de conhecimento para outro.

Nesse sentido, essa coletânea de trabalhos científicos traz o estado da arte em ACT, cobrindo ideias-chave, histórias, e a metodologia de algumas comunidades de trabalho, incluindo Engenharia de Sistemas Cognitivos, análise do trabalho na Europa, etnografia, fatores humanos e socioética. Todas com representativas contribuições de um seleto grupo de profissionais que articulam a ACT às teorias relacionadas às comunidades de trabalho, mostrando que várias comunidades de prática compartilham o mesmo universo científico, muito embora apresentem diferenças distintas em termos teóricos.

Portanto, recomenda-se a leitura dessa obra a todos aqueles que procuram pesquisar ou usar os conhecimentos relacionados à CTA aplicada às comunidades de trabalho, em qualquer área, uma vez que essas comunidades 
existem em todos os lugares e, na maioria dos casos, os indivíduos pertencem e atuam em mais de uma delas simultaneamente (no trabalho, na escola, em casa, etc.). Umas têm nome, outras não; algumas são grandes, outras pequenas; muitas são locais, algumas são globais; muitas estão dentro de organizações e muitas incluem membros de várias organizaçóes; algumas apresentam interatividade face a face; em outras, essa interação se efetua virtualmente; em algumas, as pessoas fazem parte mais intimamente e, em outras, mais perifericamente; algumas são reconhecidas formalmente e outras, muitas, vivem na completa informalidade e são invisíveis.

Concluindo, esse volume, permeado pelas palavras, pesquisas e experiências de vários estudiosos, revela-se de extrema relevância por sinalizar que as informaçôes e materiais desenvolvidos para treinamento em ACT são precisos e preciosos para o propósito a que se destinam, tornando a usabilidade, nessa área, accessível aos profissionais. 